\title{
MAPEO DE LAS PRODUCCIONES DEL CLÚSTER AUDIOVISUAL DE LA PROVINCIA DE BUENOS AIRES (CAPBA) EN LOS FESTIVALES
}

\author{
Mapping of the Clúster Audiovisual de la Provincia de Buenos Aires (CAPBA) \\ productions at festivals
}

Jimena Cecilia Trombetta*

https://orcid.org/0000-0003-1317-1178

\begin{abstract}
Resumen
Investigar las producciones del Clúster Audiovisual de la Provincia de Buenos Aires (CAPBA) implica bastante más que abordar la filmografía de ese espacio. Supone estudiar vínculos interregionales e internacionales afianzados en diversos festivales que dan por resultado un fenómeno expansivo que nutre redes cuestionadoras de las estéticas y prácticas industriales. En el presente artículo proponemos estudiar el fenómeno del CAPBA desde cuatro ejes. El primero aborda la productora Cinebruto antes de la creación del CAPBA. El segundo desarrolla la historia y las particularidades del clúster y cómo se expande hacia la creación y/o apoyo de nuevas redes. El tercero indaga sobre la creación de los festivales y las nuevas relaciones impulsadas por la Red. El cuarto eje se enfoca en los nuevos formatos y las diversidades estéticas. Con la finalidad de realizar un mapeo del fenómeno retomamos reflexiones en torno al regionalismo desarrolladas en el campo de los estudios históricos y culturales, bibliografía relacionada con los modos de producción y de representación en el campo del cine, los anuarios realizados por el CAPBA y los diversos catálogos de festivales en los que el Clúster participó.
\end{abstract}

$<$ Regionalismo $><$ Cine comunitario $><$ CAPBA $><$ Rizoma $>$

\begin{abstract}
Research of the "Clúster Audiovisual de la Provincia de Buenos Aires (CAPBA)" productions involves much more than addressing its filmography. It involves studying interregional and international links established in various festivals. This results in an expansive phenomenon that feeds the questioning networks of the industry and its aesthetics. In this article we propose to study the CAPBA phenomenon from four axes. The first deals with the Cinebruto production company before the creation of CAPBA. The second develops the history and peculiarities of the Cluster and how it expands towards the creation and support of the new networks. The third inquires about the creation of festivals and the new relationships promoted by the Red. The fourth axis focuses on new formats and aesthetic diversities. In order to map the phenomenon, we return to reflections on regionalism developed in the field of historical and cultural studies, bibliography related to modes of production and representation in the field of cinema, the yearbooks produced by CAPBA, and the various catalogs of festivals in which the Cluster participated.

$$
<\text { Regionalism }><\text { Community cinema }><\text { CAPBA }><\text { Rhizome }>
$$

Recibido: 28/09/2020//Aceptado: 25/11/2020

* Instituto de Historia del Arte Argentino y Latinoamericano, Facultad de Filosofía y Letras, Universidad de Buenos Aires (UBA), Argentina, jimenacecilia83@gmail.com
\end{abstract}


Trombetta. Mapeo de las producciones del Clúster Audiovisual de la Provincia de Buenos Aires (CAPBA) en...

\section{Introducción}

Estudiar el movimiento del Clúster Audiovisual de la Provincia de Buenos Aires (CAPBA) y sus producciones implica bastante más que abordar la filmografía concretada al interior de ese espacio. Significa investigar sobre el clúster fundado como Asociación civil en el año 2013, en gran medida gracias a uno de sus impulsores, José Celestino Campusano, quien estuvo acompañado en esa empresa por los cofundadores Horacio Florentín, Mauro Altschuler y Carlos Lasso. Supone conocer, a su vez, un movimiento colectivo de realizadores que acercaron sus materiales a festivales surgidos de un impulso comunitario, sin desdeñar otros espacios de exhibición ya instalados en el campo cinematográfico argentino en distintos momentos de su historia. Implica comprender que ese clúster es parte de una red aún mayor, que fue gestándose mediante propuestas que fomentan diversidad de estéticas que se exhiben y circulan en numerosos festivales y que conforman vínculos interregionales e internacionales. Lo cual dio por resultado un fenómeno expansivo que comparte el cuestionamiento de las estéticas consagradas y las prácticas industriales. Con la finalidad de desarrollar estos aspectos y de realizar un mapeo de este nutrido fenómeno, tomaremos teorías en torno al regionalismo (desarrolladas en nuestro país en las últimas décadas en el campo de las disciplinas de la historia, la geografía y los estudios culturales) y estudios cinematográficos (especializados en las problemáticas que nos ocupan). Asimismo, dentro de la pesquisa utilizamos como fuentes los anuarios realizados por el CAPBA, los diversos catálogos de festivales en los que el clúster participó para revisar algunas producciones filmográficas realizadas en el marco del mismo.

Para realizar ese mapeo nos interesa tener en cuenta algunos conceptos teóricos, con los que venimos trabajando en otros artículos ${ }^{1}$. Puntualmente concebimos la idea de región desde el concepto de "región histórica", que propone Heredia (1997), en tanto que la misma no se circunscribe a un espacio-tiempo, a una localidad o área circunscripta, sino que se expande justamente con el transcurrir histórico, con las inflexiones y movilidades de los agentes culturales y cinematográficos implicados en la producción fílmica. En esta línea nos interesa retomar una idea fuerza que acerca el Heredia (2012): las regiones no se vinculan solo como colonizadas "por la región central" (p. 23), sino que también se vinculan con otras regiones desplazadas hacia la periferia. De este modo, hemos hallado dos movimientos regionales que plantean una dinámica de relaciones dentro del mapa que atraviesa el clúster tratado, uno de orden centrífugo y otro de carácter centrípeto. El primero expande sus producciones acercando las prácticas sociales de su comunidad a otras regiones; el segundo, desde su localidad, realiza acciones culturales como la creación de un festival para nutrirse de otros movimientos regionales y/o combinarlos con sus propias visiones estéticas y prácticas de creación. A su vez tomaremos como concepto complementario el término rizoma definido por Deleuze y Guattari (2004). El mismo se compone como una estructura que, a pesar de poder detectarle un origen, se

\footnotetext{
Nos referimos a los conceptos de fenómeno regional centrífugo y fenómeno regional centrípeto que implementamos en otro artículo (Trombetta, 2019).
} 
desdibuja frente a la expansión de nuevos núcleos (diversos clústeres, en este caso) con múltiples derivaciones (diferentes improntas).

De acuerdo con las problemáticas mencionadas y la propuesta teóricometodológica señalada, el artículo se estructura a partir de cuatro ejes. El primero va a estudiar el origen de la productora Cinebruto y su participación en festivales nacionales e internacionales, antes de la creación del Clúster Audiovisual de la Provincia de Buenos Aires. El segundo estudiará propiamente la historia y las particularidades del CAPBA, sus dinámicas internas y cómo se expande hacia la creación y/o apoyo de nuevas redes. En el tercer eje se indagará cómo esas dinámicas propulsaron, a su vez, la creación de Festivales propios del CAPBA que habilitaron incluso la experimentación de nuevos formatos. El cuarto eje se enfocará en la diversidad de estéticas dentro de la red y la incorporación de nuevos formatos en las producciones.

\section{José Celestino Campusano y los comienzos de Cinebruto}

José Celestino Campusano, realizador y productor, es conocido por la creación de su productora Cinebruto y por ser cofundador e integrante del Clúster Audiovisual de la Provincia de Buenos Aires. Desde su dinámica de producción comunitaria, podemos dar cuenta de una periodización, ya trabajada por Oliva (2017), que lo lleva desde una comunidad más cerrada, alojada en el partido de Quilmes (situado en el sudoeste de la provincia de Buenos Aires) con la que conformó su productora, hacia una red comunitaria ${ }^{2}$ y heterogénea que propició el foco del clúster y, más adelante, el impulso de la red de clústeres internacionales. En esta periodización también podemos establecer un mapeo histórico de los festivales en los cuales tuvo participación. Por ejemplo, Verano del Ángel (2004) y Vil romance (2008) participaron de las ediciones 2006 y 2008 del Festival Cine con Vecinos de Saladillo, y fueron parte del Festival Internacional de Mar del Plata (2008), Pantalla Pinamar (2009), tanto como de Festivales en Francia y Suecia. En tanto, sus primeros cortometrajes y mediometrajes La caza de la nutria (1986), Ferrocentauros (1991), Culto suburbano de práctica individual (2002) y Bosques $^{3}$ (2005), que codirigió con Gianfranco Quattrini, no contaron con una productora detrás que los contuviera, ni con ningún tipo de apoyo institucional o con espacios de exhibición particulares. Mencionamos, tal como lo señala Oliva (2017), los primeros gérmenes de la trayectoria y la estética de Cinebruto.

Con la inauguración de esta productora en 2006, luego de realizar Legión, tribus urbanas motorizadas (2006) — primer largometraje documental—, ese material visitó festivales nacionales (Festival Internacional de Cine de Mar del Plata, Sección Documental Latinoamericano, marzo 2006; Festival Latinoamericano de Cine San

\footnotetext{
2 Consideramos comunitario el movimiento que "sienta las bases de esta praxis renovadora, y se erige en calidad de manifiesto estético donde se involucra tanto a los sujetos sociales que participan de la producción del filme, como también a aquellos que serán movilizados a implicarse activamente desde la recepción, impactando de este modo sobre el sitio del espectador pasivo, base de sustentación del modelo comunicativo implementado por el cine-espectáculo" (Campodónico, 2014, p. 75).

3 Dicho mediometraje formó parte del $3^{\circ}$ Festival Nacional de Cine con vecinos 2006 (Argentina) y ganó el premio Mejor Director $3^{\circ}$ Festival Nacional de Cine con vecinos 2006.
} 
Rafael, Mendoza, octubre 2006), lo que, si bien da cuenta de una relación interregional, aún no empieza a plasmar una estructura rizomática, con desplazamientos impredecibles en su esquema, sino el movimiento centrífugo entre regiones. En esta etapa, Campusano se constituye como individuo de referencia unívoca. En este período en que comienza a funcionar la productora, su estética está enmarcada en sus lineamientos personales y el movimiento centrífugo concentrado en las participaciones de sus films en los festivales. Con el paso del tiempo este proceso se irá ramificando hasta transformarse en una estructura arbórea, con el reconocimiento de Campusano como fuente inspiradora de otros creadores que lo replican. Un ejemplo, entre muchos, que ya perfila una estructura más abierta es el film Paraíso de sangre (2011). Producido por José Celestino Campusano y Sebastián Mónaco, y dirigido por ambos y Ángel Barrera, en su estética se observa la presencia de Cinebruto. Pero, a su vez, esa manera de narrar anclada en Campusano se extiende a Mónaco en sus otros dos films - Peanuts one dollar (2010) y Positivo (2015) - en los que ya no estará presente esta productora. Desde entonces, las dinámicas de ramificación que mantienen un tronco común comienzan a ser perceptibles en el campo de la producción y en el plano estilístico, con la presencia, directa o tácita, del cineasta quilmeño. Finalmente, con la fundación del CAPBA, estos movimientos mutarán hacia un esquema múltiple y de mayor heterogeneidad.

\section{La actitud centrífuga de Cinebruto. La expansión de los films en nuevos circuitos de festivales}

Desde sus inicios, la productora fundada por Campusano se plantea como un espacio comunitario, entendiendo este como un vehículo para dar cuenta de relatos y prácticas expresivas, que no son contemplados dentro de la industria cinematográfica.

Se comienza a gestar un proceso por el cual se tensionan las relaciones entre un modo de organizar la producción a partir de conductas asociativistas y la centralización de la producción y del producto en la figura del director, que puede ser considerado un autor que establece vínculos con instituciones y mecanismos del circuito oficial, industrial y/ o comercial. Es una etapa de consolidación ética y estética en la cual Campusano y sus colegas fortalecen el trabajo colectivo y cooperativo como herramienta esencial y necesaria para producir cine (Oliva, 2017, p. 140).

De este modo, ya sea en lo que atañe a las personas involucradas en la realización de los films como en las representaciones, da lugar a historias y a rostros y cuerpos marginados, grupos minoritarios, no usualmente convocados en el campo cinematográfico nacional, que emergen mostrando una multiplicidad de opciones. Estas búsquedas ponen de manifiesto el movimiento centrífugo de la productora radicada originalmente en una locación específica, habilitando estos patrones de relaciones la apertura de la estructura rizomática propia de los fenómenos comunitarios y 
colaborativos. Esto se ve fortalecido por una práctica temprana de la productora, la que consiste en expandir su cine en un circuito ampliado de festivales, desde los nacionales y regionales, hacia los internacionales.

Un ejemplo de esto es la experiencia que se realizó a partir de Vil Romance, que narra la historia de Roberto, un joven gay y desempleado que transita un romance conflictivo con otro hombre. Este film, que obtuvo el apoyo del Instituto Nacional de Cine y Artes Audiovisuales (INCAA) en el 2008, participó de diversos festivales que enfocaban su interés a las cuestiones de género entre los que se encuentran el $9^{\circ}$ Festival Internacional de Cine Gay y Lésbico de Barcelona (España), 14 LesGaiCine Madrid (España), $9^{\circ}$ Festival Internacional de cine Gay \& Lesbiano de Grenoble (Francia), "NewFest" New York Lesbian, Gay, Bisexual, \& Transgender Film Festival (USA), Diversa Festival Internacional de cine Gay / Lésbico / Trans de Argentina (Argentina), Mix México: Festival de diversidad sexual en cine y video (México) y Ciclo Rosa 2009 (Colombia). A su vez, fue parte de festivales nacionales ya consagrados en el campo cinematográfico tales como el 23* Festival Internacional de Cine de Mar del Plata 2008 y Pantalla Pinamar 2009; y de festivales nacionales periféricos: en este caso nos referimos al Festival de Cine y Video Río Negro Proyecta, $5^{\circ}$ Festival Nacional de Cine con Vecinos Saladillo 2008, UNCIPAR XXXI, Jornadas Argentinas de Cine y Video Independiente Villa Gesell, Festival Tucumán Cine 2009. Sin embargo, la circulación de la película fue mucho más extensa, cobrando un importante papel en su visibilización y legitimidad su presencia en festivales internacionales. ${ }^{4}$

El otro film que impactó a gran escala en múltiples festivales nacionales y extranjeros fue Vikingo, un largometraje de ficción del año 2008, que se sostuvo con el apoyo del INCAA y la producción de Cinebruto. Participó dos veces del Festival Internacional de Cine de Mar del Plata (ediciones 2008 y 2009), primero en la sección Work in Progress y luego en la Competencia Oficial Internacional. Asimismo, formó parte de Pantalla Pinamar 2010. Más allá de estos dos espacios reconocidos a nivel nacional, se exhibió en una serie de festivales periféricos entre los que se encuentran el $2^{\circ}$ Festival Río Negro Proyecta-Bariloche Competencia Nacional 2010, y Tucumán Cine 2010 Competencia Nacional. Nuevamente, la circulación no se limitó al territorio argentino, sino que se extendió a diversos países latinoamericanos y europeos. En el circuito exterior, se puede diferenciar la participación en festivales que están legitimados dentro del campo audiovisual, de otros que se muestran como alternativas para films poco visibilizados. En el primer caso, podemos mencionar el Hamburg Film Fest2010 (Alemania), $26^{\circ}$ Warsaw Film Festival, 2010 (Polonia), $29^{\circ}$ Festival Cinematográfico Internacional del Uruguay 2011 (Uruguay), 20 ${ }^{\circ}$ Festival de Cine Latinoamericano de

\footnotetext{
${ }^{4}$ Dentro de los internacionales se encuentran: 17 $7^{\circ}$ FilmFest Hamburg 2010 (Alemania), $18^{\circ}$ Festival Biarritz 2010 (Francia), 35 ${ }^{\circ}$ Festival de Cine Iberoamericano de Huelva 2010 (España), $21^{\circ}$ Encuentro de Cine Latinoamericano de Toulouse 2010 (Francia), 4 Muestra de Cine Argentino en Leipzig 2010 (Alemania) Black Movie Festival-Ginebra 2010 (Suiza), $28^{\circ}$ Festival Cinematográfico Internacional del Uruguay 2010 (Uruguay), 17 Febiofest-Festival Internacional de Cine de Praga 2010 (República Checa), $13^{\circ}$ Cine Las Américas International Film Festival Austin 2010 (USA), y EuroPride Festival Warsaw 2010 (Polonia).
} 
Trombetta. Mapeo de las producciones del Clúster Audiovisual de la Provincia de Buenos Aires (CAPBA) en...

Biarritz 2011 (Francia). En el segundo, consideramos al 14 Festival de Lima, Encuentro de Cine Latinoamericano Sección Secretos y Tesoros de Latinoamérica 2010 (Perú), Festival Cine B Santiago 2010 (Chile), y el $23^{\circ}$ Encuentro de Cine Latinoamericano de Toulouse 2011 (Francia).

Los dos films componen una serie de patrones estéticos que dan cuenta de las marcas enunciativas, de un locus enunciativo en términos de Heredia (en Molina y Varela, 2018). Esto se puede observar en la edificación de personajes que, remitiéndonos a la sociedad argentina del año 2008, se caracterizan por una constitución socio-política específica y por formar parte de grupos minoritarios que entonces, y aún hoy, luchan por sus derechos. Recordemos que durante el gobierno de Cristina Fernández de Kirchner se dictaminó la Ley de matrimonio igualitario en 2010, luego de haberse obtenido un primer logro en este camino en 2002 (la unión civil), al que lo habían precedido un sinfín de reclamos desde los años 90 . La importancia de este hecho, y su proceso histórico, dio lugar a que se habilitaran espacios de reflexión y de difusión en la cultura, entre ellos los festivales que adoptaron como eje esas temáticas. La empresa Cinebruto, lejos de estar desatenta a los fenómenos sociales emergentes, realizó un film que toma al colectivo LGTBIQ como una minoría acallada en la época, complejizando la trama al situarla en los barrios obreros de la provincia de Buenos Aires. En tal sentido, la naturaleza expansiva de este fenómeno cinematográfico puede ser entendido en dos dimensiones: una relacionada con la representación de un entorno y de grupos marginales - tema que abordaremos en profundidad más adelante- $\mathrm{y}$ la segunda asociada al fortalecimiento de la exhibición y la circulación de los films en los espacios nacionales, regionales e internacionales. En este sentido, el apoyo financiero del INCAA, así como los premios otorgados por esta institución, siempre fueron utilizados en función de afianzar la visibilidad de los sectores sociales usualmente desplazados. Entonces, ya desde sus comienzos, lo regional es en este caso la lucha por lo simbólico y la composición de un locus regional (Heredia en Molina y Varela 2018), es decir “(...) los discursos sociales (que) se configuran cultural y simbólicamente en una "enunciación regionalizada" (p. 62).

\section{La historia del CAPBA y la creación de múltiples espacios y asociaciones}

Por lo analizado hasta este momento, interpretamos que la tendencia estética y de producción de la empresa Cinebruto comenzó siendo homogénea, para luego ampliarse, ubicándose entre las razones que incidieron en estas decisiones la pronta vinculación de los agentes creadores con otras productoras y cineastas, con otras tecnologías y con espacios de exhibición diferentes. Como se señaló en un artículo previo: "Lo que comienza de la mano de Cinebruto se terminó extendiendo hacia los diversos convenios generados con otras productoras tales como Estudio Chroma, Ñoño, Escafandra RV, Cejitango, Inimaginaria, Alud, MVM, Helkin, Titanio, Gandhi y Lahaye post" (Trombetta, 2020, p. s/d). Estas empresas, creadas en diversas fechas, en algunos casos copresididas por Campusano - así surgió Estudio Chroma, por iniciativa de Horacio Florentín y Campusano-, delatan el nivel de expansión que se propuso 
el Clúster Audiovisual de la Provincia de Buenos Aires, el que se constituyó como asociación civil sin fines de lucro el 28 de enero de $2013 .^{5}$

A partir de entonces la producción de Cinebruto comenzó a entrelazarse con las diferentes acciones postuladas desde el clúster, sentándose las bases de una estructura rizomática que empezó a cumplir los principios propuestos en la conceptualización realizada por Deleuze-Guattari (2004, p. 13): "Principios de conexión y de heterogeneidad: cualquier punto del rizoma puede ser conectado con cualquier otro, $\mathrm{y}$ debe serlo". De igual forma, en el CAPBA se actualiza otro de los principios centrales de esta estructura, el de la multiplicidad, donde el Uno forma parte de un sistema más amplio, pero no define al Dos. En este sentido, tenemos que considerar que el Uno (uno de sus fundadores, Campusano) es parte del nuevo espacio, pero no define la estética de los diversos integrantes que lo conforman. Por otra parte, la creación del CAPBA y su constitución en red fueron factores que habilitaron la expansión de la cinematografía local y regional hacia otros terrenos, tanto como la heterogeneidad de las perspectivas cinematográficas y estéticas englobadas.

En lo que respecta a la propagación en red, prontamente el CAPBA puso foco en varias ciudades de la Argentina (Mar del Plata, La Plata, Bariloche, Rosario) y en toda la región Noreste del país. Simultáneamente, se extendió a México, Brasil y Bolivia, con la presencia en múltiples espacios: Festival Distrital (México), Festival Pachamama (Brasil) y Festival Aynivisual (Bolivia). En este sentido, el concepto de rizoma va en confluencia con el concepto benjaminiano de constelación que aplica Serafini (2018) al estudio de los festivales. La autora señala que la nueva dinámica de los festivales surge como una alternativa al centro del país, en particular al Buenos Aires Festival Internacional de Cine Independiente (BAFICI), celebrado anualmente en la Ciudad Autónoma de Buenos Aires. Me interesa agregar, siguiendo la lógica de Serafini (2018), que el movimiento del CAPBA y la Red se constituyen, igualmente, con el propósito de crear espacios de exhibición para el cine comunitario, en contraposición de las perspectivas del BAFICI que privilegia el cine independiente de autor.

Lo que podemos dilucidar, de este rizoma cinematográfico, es que estos múltiples clústeres han generado un nuevo mapa en el campo audiovisual. Este mapeo funciona, tal como explican Deleuze y Guattari (2004), bajo los principios de cartografía y calcomanía. En el libro Mil mesetas, los autores reafirman los conceptos de mapa y cartografía y desestiman el mecanismo de calco en relación al rizoma. Mientras que el calco corresponde a una estructura arbórea, "El mapa es abierto, conectable en todas sus dimensiones, desmontable, alterable, susceptible de recibir constantemente modificaciones. Puede ser roto, alterado, adaptarse a distintos montajes, iniciado por un individuo, un grupo, una formación social" (2004, pp. 17-18). De acuerdo con estas ideas, el mapa, el CAPBA se entrelaza mediante convenios con instituciones de

${ }^{5}$ El Clúster se formó en El Pato, partido de Berazategui, Provincia de Buenos Aires. Su nómina de fundadores incluyó a: José Celestino Campusano (presidente), Mario Altschuler (vicepresidente), María Soledad Bianchi (secretaria de la asamblea), Horacio Florentín y Gonzalo Rafael Padín (asambleístas). La junta conformó un estatuto formulando deberes y atribuciones de los integrantes y condiciones de ingreso para nuevos socios, el que luego fue renovado en marzo de 2013 (Trombetta, 2020). 
Trombetta. Mapeo de las producciones del Clúster Audiovisual de la Provincia de Buenos Aires (CAPBA) en...

diversas características, las cuales les brindan diferentes funciones y espacios para sus actividades. Entre estas se ubican las oficinas Festivales Buenos Aires (FEBA), la Asociación Argentina de Teledifusoras Pymes y Comunitarias (AATECO), el Festival Internacional de Cine de Mar del Plata, Parques Nacionales Bariloche, el Teatro Universidad Nacional de La Plata, y la Plataforma No solo en cines.

En lo que respecta al derrotero de la productora Cinebruto, hubo desde entonces una serie de films que se produjeron con apoyos de productoras e instituciones nacionales y/o que obtuvieron premios por parte de festivales ya reconocidos. En este sentido, no podemos pensar que la productora se encontraba por fuera del sistema o marginada, sino que los apoyos institucionales no definían ni los contenidos ni las prácticas comunitarias. Por otro lado, hay que comprender que las temáticas que la productora tenía como preferencia, coincidió con un contexto histórico-político en el que ese tipo de movimientos comenzaba a ser apoyado. Nos interesa del conjunto destacar aquellas que cumplen con varios de los puntos señalados. Fango (2012) ${ }^{6}$ recibió apoyo de Cinectud España, del CAPBA y del INCAA y a su vez Campusano fue premiado por ese film en el Festival Internacional de Cine de Mar del Plata en 2012. Resultado que impactó en la posterior gira por diversos festivales nacionales e internacionales con adquisición de nuevos premios. Fantasmas de la ruta (2014), ${ }^{7}$ también apoyado por el INCAA y por el Consejo Asesor del Sistema de Televisión Digital Terrestre, obtuvo pantalla en el Festival Internacional de Cine de Mar del Plata, y esta visibilidad en el 2014 se expandió al BAFICI, a Pantalla Pinamar y a Lima Independiente Internacional de Cine. El Perro Molina $(2015)^{8}$ fue otro de los films que recibió apoyo por parte del INCAA, al que se le sumó el sostén de la Municipalidad de Marcos Paz y el CAPBA. Dentro del recorrido de exhibición que realizó el film podemos observar que predominaron aquellos que se sitúan como espacios de legitimación centrales en el campo cinematográfico. Placer y martirio (2015) ${ }^{9}$, amparado por el INCAA, tuvo participación y premio en el BAFICI, pero debemos resaltar la particularidad de que formó parte del $4^{\circ}$ Festival de

\footnotetext{
${ }_{6}^{6}$ Nos interesa acercar los datos que dan cuenta del impacto que logró: $3^{\circ}$ Festival Internacional de Cine Independiente de Cosquín 2013 (Argentina); $3^{\circ}$ Lima Independiente Festival Internacional de Cine Lima 2013 Película invitada apertura (Perú); $21^{\circ}$ Filmfest Hamburg 2013 Sección Vitrina (Alemania); $20^{\circ}$ Festival Internacional de Cine de Valdivia 2013 Competencia Internacional (Chile); $2^{\circ}$ Festival Cine Global 2013 (Argentina); $3^{\circ}$ Festival Online Márgenes 2013 (España); Premios: Premio Especial del Jurado $20^{\circ}$ Festival Internacional de Cine de Valdivia 2013; Premios: Mejor Director $2^{\circ}$ Festival Cine Global 2013 (Argentina); Mejor Película $3^{\circ}$ Festival Online Márgenes 2013 (España); Mejor Película de Ficción - Mejor Obra Nacional 3 Festival Internacional de Cine Independiente de Cosquín 2013.

7 Cabe destacar que fue premiada por: Argentores; Asociación de Cronistas Cinematográficos de la Argentina; Mención especial SIGNIS (Asociación Católica Mundial para la comunicación); Balance de Plata otorgado por el público y la crítica cinematográfica $10^{\circ}$ Pantalla Pinamar 2014; Competencia internacional Jurado Joven: Mejor Película $4^{\circ}$ Lima Independiente Festival Internacional de Cine 2014.

8 Festivales: 29 $9^{\circ}$ Festival Internacional de Cine de Mar del Plata 2015 Competencia Internacional (Argentina); Pantalla Pinamar 2015 (Argentina); LASA Film Fest 2015 (Puerto Rico); Tucumán Cine 2015 Competencia Oficial (Argentina); 5 Festival Lima Independiente 2015 (Perú). Obtuvo el Premio SIGNIS Pantalla Pinamar 2015.

9 Premios: Mejor Director $17^{\circ} \mathrm{BAFICI}$ Buenos Aires Festival Internacional de Cine Independiente 2015; Ganadora Premio Ícaro Internacional 2015 ( $18^{\circ}$ Ícaro Festival Internacional de Cine en Centroamérica, Antigua) (Guatemala).
} 
Cine Nacional Leonardo Favio, Bolívar (Argentina), un festival que se ubica por fuera de aquellos espacios ya legitimados y conocidos. En El sacrificio de Nehuen Puyelli (2016) se repite el apoyo del INCAA y se suma la participación del Clúster de Bariloche al CAPBA y a Cinebruto, para finalmente participar en 2016 del Festival Internacional de Cine de Mar del Plata. Por último El silencio a gritos (2018) recibió el apoyo del Clúster de Bolivia en coproducción con el CAPBA y participó del BAFICI en 2018.

Sin embargo, la experiencia de Cinebruto, y en particular el apoyo recibido por parte de instituciones ya afianzadas en el campo cinematográfico, es una entre los numerosos lazos que se pueden recabar en el detalle de realizaciones presente en el Anuario del CAPBA de 2016. La multiplicidad, lo rizomático de este fenómeno, se hace presente en la combinación de productoras, en las relaciones con diversos festivales nacionales e internacionales, y en la convivencia de estéticas dentro del clúster. Es allí donde sostenemos fervientemente que la estructura no es arbórea, ya que Campusano es su impulsor, pero no dicta el camino a seguir. Tengamos en cuenta, como señala Molfetta, que:

el CC (cine comunitario) ${ }^{10}$ trabaja en los términos de la revolución molecular, por tratarse de un proceso de cambio social capilar, de base, rizomático, en el campo de una subjetividad socialmente entendida, un cambio llevado a cabo por el accionar de una máquina revolucionaria llamada cine, que multiplica y direcciona las voces, caracterizando así una lucha dentro de lo que se concibe como semio-capitalismo. Multiplicar los lugares de enunciación es multiplicar los discursos, entendidos como conglomerados singulares de poder; y así, la noción de poder pierde su carácter esencialista, su cosificación en el Estado, para convertirse en algo que se produce en el seno mismo de la semiosis social, y en todos los niveles: del infra-personal al interpersonal y comunitario (2015, p, 93).

El CAPBA se constituye como un clúster plural desde su fundación, no solo porque es una institución organizada mediante un sistema de comisiones, sino también porque parte de sus socios fundadores (Horacio Florentín, Mauro Altschuler, Carlos Lasso y el propio Campusano) generaron producciones con diversidad de estéticas, desde distintas productoras, e impulsaron varios festivales, entre ellos el Festival Cine con Riesgo presidido por Lasso, el Fi-Ci-Prox (2015) y el FIRA inaugurado por Campusano. El primero en Colombia y el otro en San Clemente del Tuyú (con sede en el Partido de la Costa, Provincia de Buenos Aires). Por otro lado, Horacio Florentín y Carlos Lasso produjeron el film dirigido por Mauro Altschuler, junto a Estudio Chroma 2 y Cejitango. Asimismo, Florentín dirigió El secreto libre (2016), producido por Campusano y una figura muy repetida dentro del Clúster: Diego Napoli, quien estuvo como productor

\footnotetext{
${ }^{10}$ El paréntesis es mío.
} 
junto a Pierrot Les Films de la obra de Wolfang Vallejo Susurros del árbol (2017). ${ }^{11}$ Estos nuevos lazos, donde el Clúster cobra vida por fuera de sus fundadores, se replica en varios films como el de Martín Alejandro Santamaría, Don Giovani (2015), producido por Micol Metzner, Federico Jacobi y el propio Diego Napoli. Este tejido se expande, si de allí desprendemos las creaciones de Metzner con Ritmos propios (2016), documental concretado junto a Néstor Saracho que obtuvo una Mención especial en el festival de Cine con Riesgo; o si traemos a la memoria el film dirigido junto a Veroka Velazquez, Oíd mortales (2016), producido gracias al premio que ganó en 2015 Placer y martirio de Campusano en el BAFICI: una cámara Red One. A su vez, esta trama mantiene lazos elásticos cuando los agentes mencionados se congregan en la producción de $L a$ secta del gatillo (2018), obra que mencionaremos más adelante. Así se cumple una de las características del rizoma: la ruptura asignificante, es decir aquel quiebre donde el rizoma se suspende en determinado espacio, pero vuelve a regenerarse. Tal como dicen de modo socarrón Deleuze y Guattari "es imposible acabar con las hormigas" (2004, p. $15)$.

Tan imposible resulta, que dieron paso a participar y apoyar festivales externos y programas de realización tales como el impulsado por Olga Tapia del Clúster de México, que conformó Talento Integrado y el Festival Distrital; el Festival Aynivisual formado desde la COMUNA de Bolivia; el Festival Pachamama en Brasil, y el Festival en Los Ángeles North American Teasers Film Future Festival (una versión del Fi-CiProx), mediante el cual gestaron vínculos con la comunidad latina de Estados Unidos (Velázquez, 2016). Estos apoyos por parte del CAPBA habilitaron coproducciones y una fluida circulación de nombres de directores y productores, que en muchos casos también ejercieron el rol de directores de arte, o bien participaron en la iluminación y el montaje, entre otros rubros. Sin ir más lejos la figura de Olga Tapia también fue productora de Contraviento (2016), un film de Abel Amador y David Villareal, que se desprendió del taller dictado por Campusano en el Distrital, México. Estos directores luego viajarían hacia el rodaje de El azote (2016), film producido por Cinebruto, para filmar el documental Cinebruto, detrás de cámara (2016). Por su parte desde el Aynivisual se filmó El silencio a gritos (2018), una coproducción entre Campusano y la COMUNA.

A todo este magma de creadores hay que sumarles los lazos de los clústeres ya fundados dentro de la nación argentina: el de la región Nea de la mano de Pablo Almirón, en Bariloche bajo la presidencia de Miguel Angel Rossi, Claudio Perrín en Rosario, Pablo y Luna en La Plata, entre otros. Sobre el Clúster Audiovisual Bariloche, por ejemplo, es de interés señalar que está integrado a la Universidad Fraternidad de Agrupaciones Santo Tomás de Aquino (FASTA), fue fundado en el 2012, y luego generó vínculo con el CAPBA involucrándose en la realización de El sacrificio de Nehuen Puyelli (2015). A su vez, Rossi filmó Sucesos perdidos (2016) y Gabriel Berdensky realizó Bajo superficie (2016). Por su parte, el NEA participó del festival de teasers con Perón contra la langosta (2016) y Colgados de los tobillos (2016). Asimismo, el

${ }^{11}$ El film se estrenó en el Cine Gaumont en el marco del Festival de Cine Inusual en Buenos Aires. 
Clúster de La Plata formó parte del programa Talento Integrado con un film de Federico Barrios: En movimiento (2016). Asimismo, el Clúster de La Plata se comprometió en 2016 con la preproducción de un largometraje de Juan Lage titulado El Ruso muere.

Estos ejemplos vienen a afianzar la observación de Heredia (1997), en la que el concepto de región, lejos de tener límites geográficos fijos, es una estructura mutable e histórica; rizomática en este caso, con movimientos tanto centrífugos como centrípetos, dadas sus relaciones interregionales e internacionales. Estos movimientos están atravesados por lazos sociales y por la amalgama de "los elementos que provienen de la observación del medio con aquellos otros que constituyen el sustrato ideológico de las personas. Ese fenómeno, es claro, se da en cada individuo en interacción con los demás individuos, y así se multiplica hasta conformar el imaginario social" (Heredia 1997, p. 83) Así, el carácter interegional, sus enlaces, muchas veces son sostenidos por una concepción de mundo similar, por rasgos que en este caso nos aúnan no desde una idea de región homogeneizadora y nacional, sino desde la combinación de diversas voces que se fueron gestando desde la otredad latinoamericana (Heredia 2012)

Figura 1. Gráfico de Red de clústeres

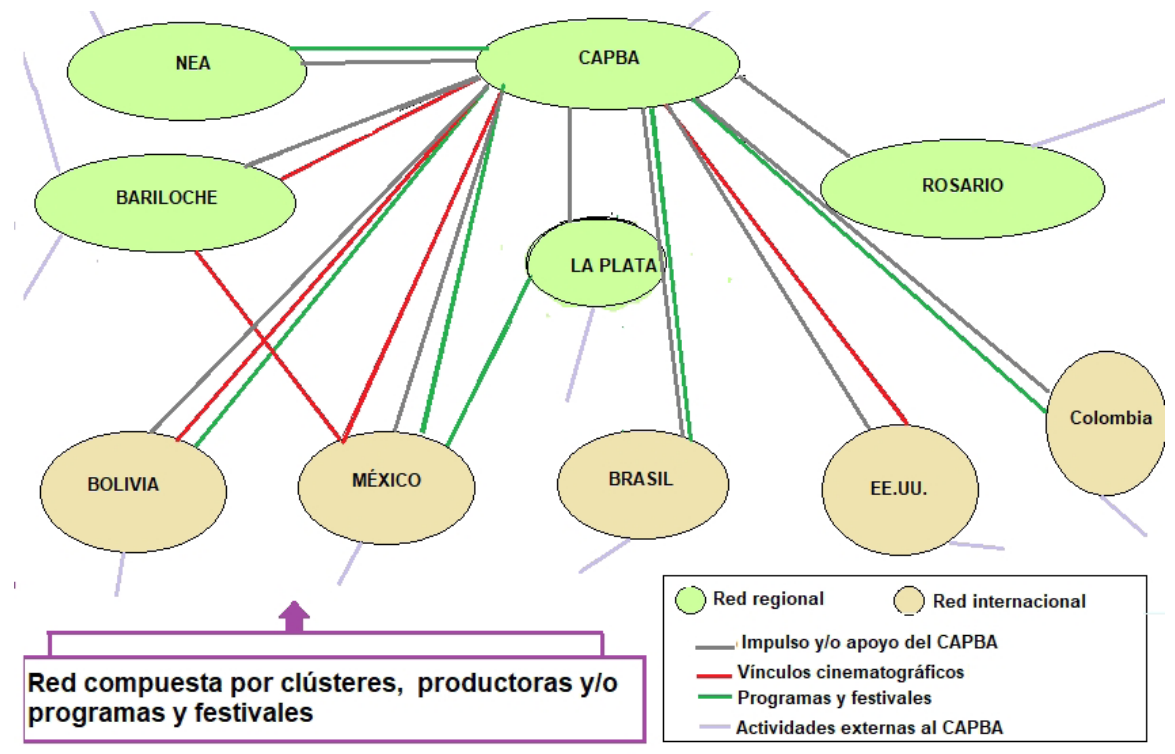

El año 2018 es un punto de quiebre que inauguró la investigación en nuevos formatos, tales como el ${ }^{\circ} 360$. Este nuevo medio de filmación amplió los espacios a participar por parte de Cinebruto. Entre otros casos, La secta del gatillo (2018), primer largometraje en ${ }^{\circ} 360$, se presentó originalmente como cortometraje en 2016 en el Festival SXSW de Texas, un espacio que acepta y se enfoca en las innovaciones tecnológicas. A su vez, Colombia fue sede del Fi-Ci-Prox y la conexión con colegas argentinos radicados en Los Ángeles dio espacio para el North American Teasers Future Festival. Así, el espíritu expansivo de Cinebruto también se observa en las experiencias con nuevos 
Trombetta. Mapeo de las producciones del Clúster Audiovisual de la Provincia de Buenos Aires (CAPBA) en...

formatos. Recordemos que La secta del gatillo es un largometraje filmado en formato ${ }^{\circ} 360$, que fue elaborado por el equipo del CAPBA con apoyo de la Municipalidad de Marcos Paz. A su vez tuvo espacio en el BAFICI y en otros festivales nacionales e internacionales ${ }^{12}$. A esta experiencia le siguió el largometraje, en el mismo formato, Brooklyn Experience (2018): el mismo fue apoyado por productoras de EE.UU, tal como Inmersivefilms, y lógicamente por el CAPBA. Tuvo exhibición en el BAFICI en 2018 y extendido al Festival Internacional de Cine de Rotterdam, Países Bajos -World Premiere, 2018. Luego, en plan de continuar los lazos rizomáticos, el nuevo formato también se hizo presente en el Clúster de La Paz (provincia de Buenos Aires), dando por resultado, junto a Cinebruto, Bolivia profunda (2018). Su producción fue apoyada por Alud, pero también por la norteamericana Inmersivefilms. Su impacto se trasladó a Europa en dos festivales: Mercado de coproducción Cinemart, Rotterdam International Film Fest-Work in Progress. Paises Bajos, 2019; Marché du film- Festival de Cannes, 2018. (Para una visión más sintetizada de los datos ver Tabla en Anexo)

\section{EI CAPBA y sus diversas estéticas}

El CAPBA, como espacio colectivo en expansión, acoge una multiplicidad de estéticas que recorren géneros y tipologías diferentes para dar a conocer diversos contenidos que enfrentan, a su vez, conflictos y coyunturas sociales de diversa índole. Con esto queremos señalar que, si bien Campusano como referencia primera se enfocó en narrar las vidas de los grupos desplazados y/o marginados del conurbano bonaerense, dentro del CAPBA los temas varían de acuerdo con sus creadores y el devenir histórico. En este sentido, la construcción de la otredad, en términos de Heredia (2012), viene desde algún lugar a poner en jaque una estructura fija del concepto de región-nación. De esta manera, encontramos continuidades y rupturas estéticas y de contenido. Lo que sí une a todos los integrantes es el modo de producción comunitario, que coliga a los desplazados de las escuelas de cine nodales radicadas en el centro de Buenos Aires.

Así, el CAPBA funciona como escuela cinematográfica y, desde esos talleres de formación, se entrenan para utilizar los nuevos formatos y aplicarlos a la creación de cada equipo de trabajo. Por ejemplo, el formato ${ }^{\circ} 360$ implica una expectación interactiva y una readaptación del ojo del espectador, que debe decidir cómo recorrer el espacio de cada escena propuesta. Hay que comprender, a su vez, que la multiplicidad de estéticas y temas retroalimenta la participación y la creación de festivales que legitimen y visibilicen esas producciones. De igual manera, este fenómeno sucede por los lazos gestados mediante las crecientes coproducciones. Entonces, a las temáticas marginales y propias del conurbano que promovió en sus orígenes el director de Cinebruto, ya estudiadas en profundidad por Lencina (2017), ${ }^{13}$ se suman temáticas relacionadas con

\footnotetext{
${ }^{12}$ Marfici, Festival Internacional de Cine Independiente de Mar del Plata, Argentina; Festival Internacional de Cine de Mar Del Plata, 2018, (Argentina); Trends (Ventana Sur), (Argentina); South by Southwest (SXSW), 2016, (USA); Rotterdam International Film Fest, Países Bajos, 2018 (Alemania); Muestra de Cine Nacional en Río Grande (Argentina); Mediamorfosis, 2018, (Argentina); Festival Internacional de Málaga, 2019 (España).

${ }^{13}$ En su artículo, la autora señala que "la representación que hacen de los sectores subalternos escapa a todo
} 
la clase media - historias de amor, conflictos sociales basados en los prejuicios de las clases más acomodadas - y registros temáticos y estéticos de nuevos lugares amparados en las coproducciones entre el CAPBA y el Clúster de Bolivia, los vínculos con Estados Unidos, el Clúster de México, y el Clúster de Bariloche.

Las diferencias temáticas se pueden encontrar dentro del propio Clúster de la Provincia de Buenos Aires. Por mencionar un ejemplo, Susurros del árbol (2017), del cineasta venezolano Wolfang Vallejos, rodada en 2016, deja entrever una puesta en escena que refleja una clase social acomodada, brinda primeros planos de los personajes que muestran cuerpos canónicos inmersos en los estándares de la publicidad y plasma imágenes limpias que se alejan de la estética del cine pobre con el que se ha comparado a las primeras creaciones de Cinebruto, en las que se destaca esa textura granulada impresa en el fotograma. No obstante, el film, con prestaciones comerciales, efectivamente fue producido y creado por parte de los integrantes del CAPBA. Mencionamos a Diego Nápoli, pero también debemos nombrar al propio Campusano como co-productor y a una figura como Federico Jacobi en la dirección de fotografía. A su vez, tanto Pablo Toporosi como Bárbara Culotta se desempeñan como artistas en el ámbito del cine y el teatro independiente. A nivel de contenido, el film toma como eje una historia de amor concentrada en el desencuentro entre Carolina y Salvador. Carolina fue la joven esposa de Julio, ${ }^{14}$ un escritor recientemente fallecido, y ex novia del hijo del escritor. Salvador, que ejerce la misma profesión que el padre, siente un gran resentimiento sobre esa relación. La historia narra los motivos del conflicto y como el vínculo entre ellos va mutando a medida que se curan las heridas de antaño. Las imágenes se suceden y habilitan, además de los planos de la casa quinta — que da cuenta de la referencia de clase-, espacios abiertos, mansos y hasta rurales, que acogen y apaciguan las tensiones familiares. En este film, hay un contrapunto regional en donde el protagonista se exilió hacia Venezuela y el director de la película procede de allí. Es a su regreso, y en el transcurrir de los diálogos, en los que dará cuenta de algunas tradiciones y palabras propias de aquel país, que queda, desde nuestro parecer, como marca propia de Wolfang Vallejos.

Como es posible comprender, las rupturas estéticas ocasionadas por las diferencias de las regiones se localizan especialmente en las coproducciones. Como ejemplo de ello podemos mencionar Exilio (Olga Tapia, s/d), la coproducción mexicano-argentina, que aún se encuentra en postproducción ${ }^{15}$. La disponibilidad del film es compleja, por este motivo ofrecemos algunos puntos específicos sobre los planos que podemos observar en un video de promoción realizado junto a Olga Tapia. Estas imágenes registran espacios de opresión, que remiten al pasado de los padres de los

tipo de estigmatización o idealización que pueda hacerse de ellos" (2017, p. 15). Ese modo de representar, aspecto clave en la producción de Cinebruto, se genera porque todo el equipo creativo es oriundo del barrio y comparten un imaginario común. Así, el registro audiovisual tiene como meta mostrar el lugar tal cual es.

${ }^{14}$ Cabe mencionar que el nombre del escritor hace homenaje a Julio Cortázar.

${ }^{15}$ La campaña de fondeo colectivo que se realizó en 2018, para dar espacio a la incorporación de la animación del artista Salvador Herrera, fue finalizada y ahora se encuentra en la etapa de diseño sonoro. 
personajes de Mauricio y Martina, inmersos en la última dictadura militar. Su sinopsis narra la vida de Mauricio, quien luego de estar exiliado en México, decide regresar a Argentina. Ya en su país busca a su media hermana, Leonora, quien al percatarse de su realidad decide refugiarse en una cabaña abandonada con la intención de reinventar su identidad. Unos pocos fotogramas dan cuenta de otra composición espacial que ofrece espacios abiertos, hasta rurales, que contienen a la cabaña inmersa entre planos generales y planos más intimistas para metaforizar el sentir de Martina.

Figura 2. Susurros del árbol, 2017

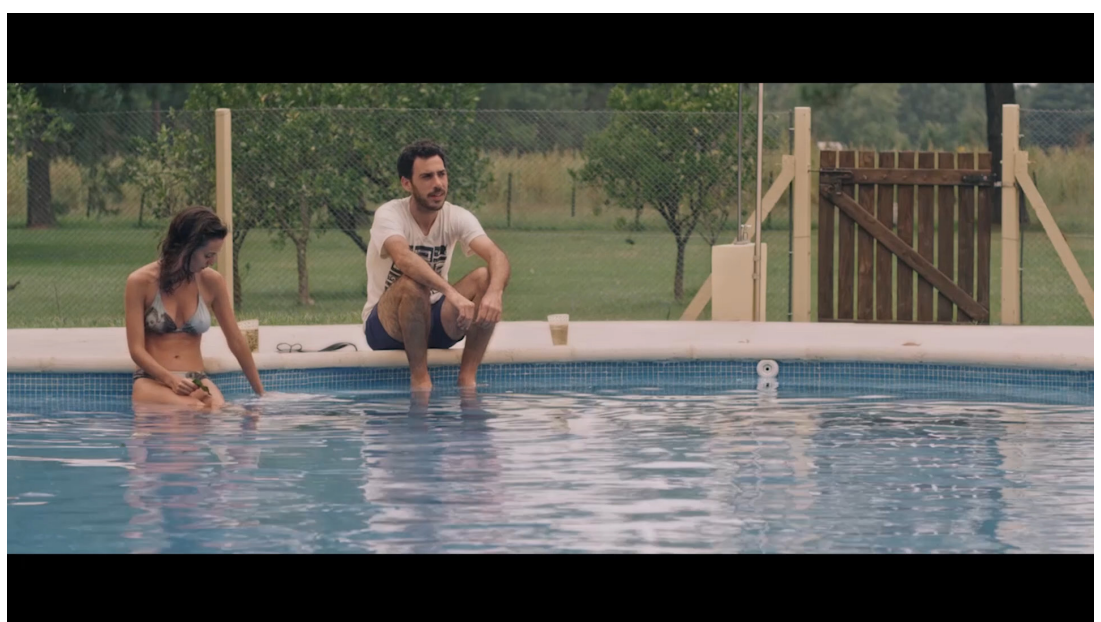

Fuente: Fotograma cedido por Wolfang Vallejos

Figura 3. Exilio, s/d.

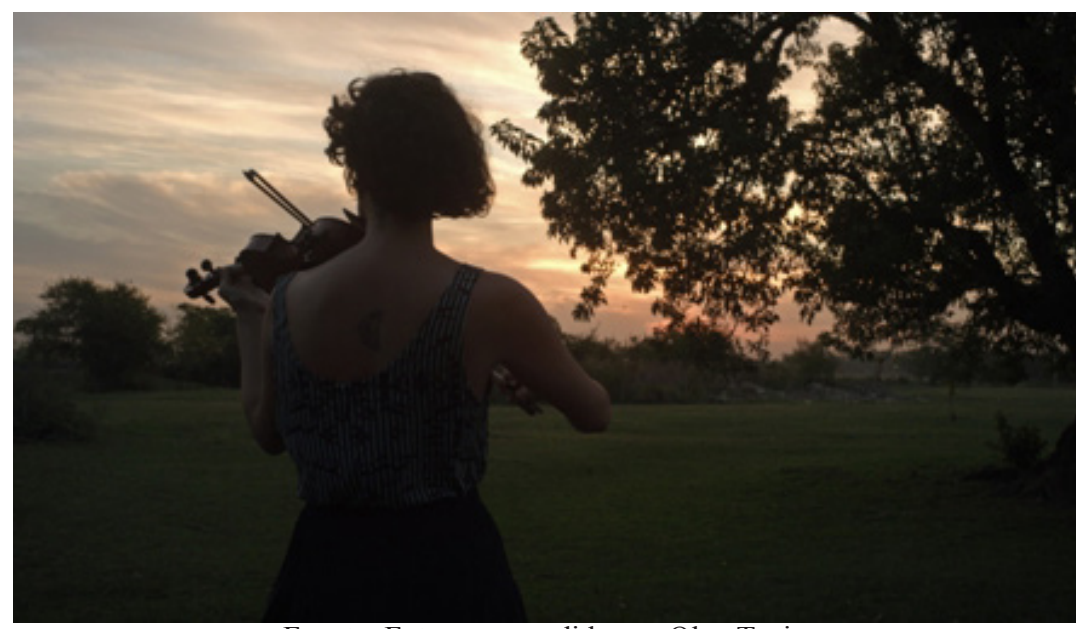

Fuente: Fotograma cedido por Olga Tapia

Otra coproducción que es factible de analizar con mayor profundidad, debido a que está disponible, es El silencio a gritos (2018). Apoyado el film por el CAPBA y por el Clúster Audiovisual de Bolivia, fue a su vez producido por Fundación Comunidad 
de Productores en Arte (COMPA). Escrito y dirigido por Campusano, incorpora en su composición los paisajes de El alto en Bolivia, una localidad dentro de la ciudad de La Paz, de la que podemos apreciar planos generales con sus cerros, con sus calles, con su ritmo citadino mixturado con rituales propios de los pobladores originarios. Además, fue actuado por los integrantes de COMPA quienes efectivamente le imprimen al film una estética diferente a los trabajos ya conocidos del director. La diversidad cultural entre Campusano y los creadores de Bolivia habilita el ingreso del lenguaje propio de la región, en una escena que resume el fuerte conflicto de incesto entre hermanos. Esta escena, en la que el padre y la madre se preguntan sobre qué no han sabido transmitir en la educación de sus hijos, sucede en el comedor de un hogar donde los colores se mantienen intactos como parte de la cultura del lugar. En este sentido, la densidad de la temática padecida en un barrio humilde no fue acompañada por la composición de un cuadro que ofrezca un espacio lúgubre, como sí podríamos recolectar en muchos de los films de la productora de Cinebruto. Sí es cierto que perviven los rasgos del cineasta quilmeño en la acción de denunciar los conflictos sociales, y de mostrar las situaciones y las vivencias de los grupos marginados en diferentes contextos.

En la línea específica de Cinebruto, podemos recordar y apuntar algunos elementos estéticos de El arrullo de la araña (2015). Campusano, director de este film, alegaba que, si bien se había realizado con algunas prestaciones del cine comercial, mantenía el espíritu del cine comunitario. Con el equipo técnico del CAPBA y elenco del mismo espacio, narran una historia que cuenta sobre el maltrato laboral en los comercios del conurbano bonaerense. Este drama se acerca a su referente con diálogos verídicos que reproducen el racismo, la xenofobia y la intolerancia entre los empleados y el patrón. El núcleo del conflicto se explicita con elementos metafóricos, como el caminar de la araña entre los barrotes de la reja del negocio. Su silencio, su arrullo, significa esos pensamientos que no se comunican entre el jefe y el empleado, hablándose entre los pares a escondidas, lejos de los espacios de control. Un primer elemento que climatiza ese ambiente, opresivo, siniestro y de control, es la música extradiegética que acompaña la historia desde el minuto cero. Ese clima descansa en planos cerrados y planos medios, que retoman los gestos de los personajes y se afianza en la tensión que se aloja en sus miradas. Además de la música y el motivo de la araña, se suman otras metáforas generadas desde la técnica. Un sumario de imágenes muestra los cuerpos de los empleados atendiendo el local, mecanizados y pendientes de ventas que no se verán reflejadas en el reconocimiento del esfuerzo laboral. Estas dinámicas aumentan en el transcurso de la trama, caldeando un ambiente que dará por resultado amenazas de la patronal, luchas por los derechos y reacciones humanas exaltadas debido al ninguneo sistemático del dueño de la ferretería.

Otro caso es el de Brooklyn experience (2018), ficción dramática coproducida por Argentina y Estados Unidos, se enfoca en abordar los problemas de la migración en Estados Unidos y cómo se conforma un ámbito de xenofobia y racismo. Este film, también dirigido por Campusano, repite algunas estructuras de denuncia social, pero la ruptura estética se da por la particularidad de que fue realizado con tecnología transmedia 
que brindó la productora Virtual ${ }^{\circ} 360$. Asimismo, ese formato acompaña los conflictos sociales que enfrentan los inmigrantes en Estados Unidos. Lógicamente, el núcleo de la trama se enmarca en una clase social media que nos recuerda directamente la casa de la clase alta de Placer y Martirio, más que a las tensiones sociales acontecidas en los barrios del conurbano. Otro quiebre fundamental que genera este film, respecto de las etapas precedentes, es la toma de posición del espectador. Si bien existe una decisión artística sobre el vestuario de los personajes, la puesta en escena, los diálogos y la música (expectante y anunciadora en este caso), el film permite que esas combinaciones sean manipuladas desde la percepción de cada espectador, que será quien decidirá qué tipo de plano generará a partir de la utilización del comando. De esta manera, nos vemos inmersos en la ficción generando micro-montajes en cada escena, estableciendo por ejemplo qué tipo de focalización crearemos sobre los personajes. Somos quien decidimos si vamos a mirar a quien habla, o si aquel quedará por fuera del cuadro.

Figura 4. El silencio a gritos, 2018.

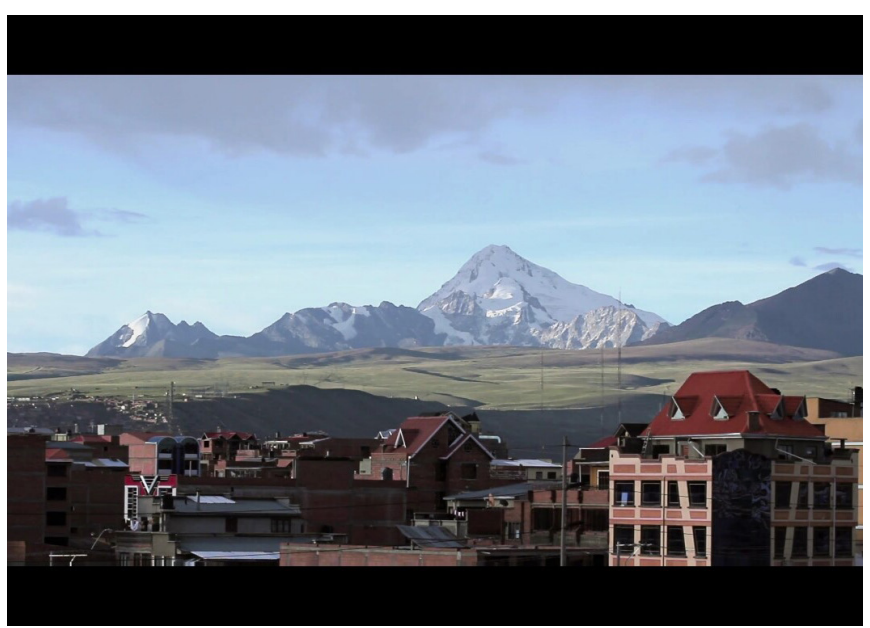

Fuente: Fotograma cedido por José C. Campusano

Figura 5. El arrullo de la araña, 2015.

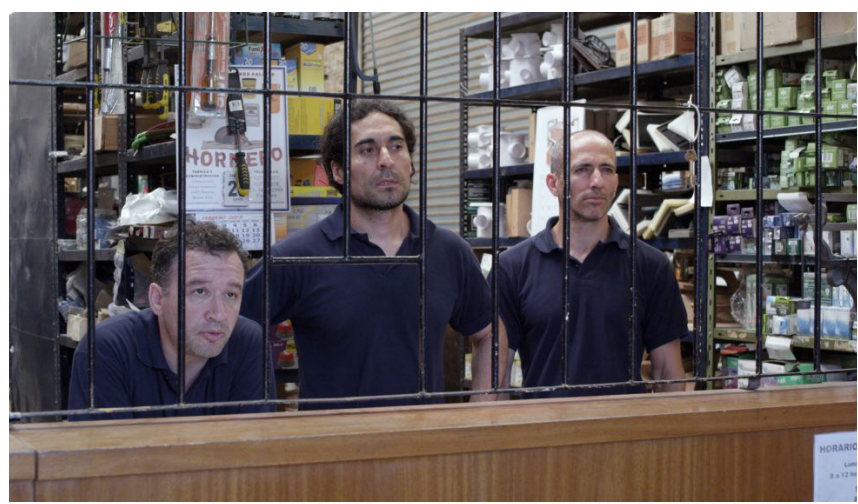

Fuente: Fotograma cedido por José C. Campusano 
Figura 6. Brooklyn experience, 2018.

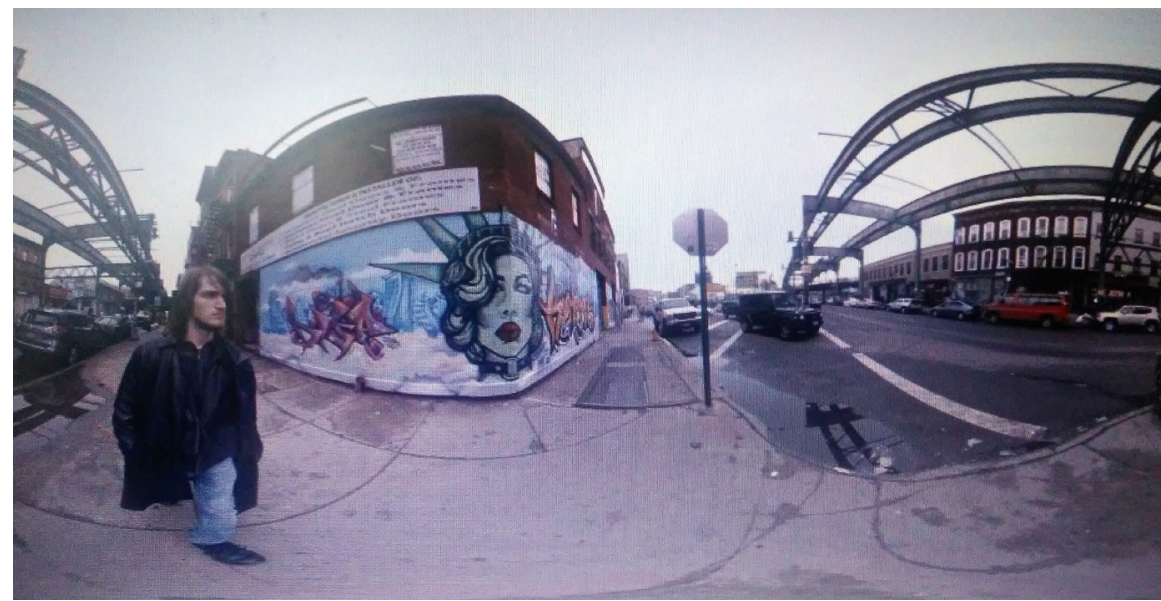

Fuente: Fotograma cedido por José C. Campusano

Estos ejemplos, son solo una muestra de las rupturas y continuidades estéticas que se sucedieron en la Red de clústeres, dentro de la productora Cinebruto, y también en la filmografía de Campusano. En relación a este cineasta en particular, cuando sus films fueron mediados por otras productoras (Virtual ${ }^{\circ} 360$ y Compa), en otros territorios (Estados Unidos y Bolivia) y con nuevas tecnologías (formato ${ }^{3} 360$ ), modificó su propuesta estética a pesar de mantener algunos ejes principales de su trabajo, como es la denuncia de los conflictos sociales. Este último aspecto puede rastrearse en el film de Olga Tapia (aún en posproducción) que, de acuerdo a lo expresado por la directora, incorporaría la animación como un recurso narrativo. Punto que introduce a un artista mexicano y conlleva un distanciamiento con la estética de Cinebruto. Es allí donde la figura de Campusano es un agente más dentro de la estructura rizomática de la red. Incluso, esta red acompaña propuestas estéticas que se desprenden por completo del eje más pregnante de este cineasta, tal es el caso de Susurros del árbol (2017) y la estética que le imprime Wolfang Vallejos a su film.

\section{Consideraciones finales}

Las conclusiones de este artículo no son un apartado cerrado, debido a que el propio fenómeno no lo es. Si dejamos por un instante la estructura rizomática propuesta, para comprender los movimientos regionales centrífugos y centrípetos que también acompañan a estos polos cinematográficos, podríamos creer que Cinebruto deviene en el CAPBA y que luego impulsa nuevos polos nacionales e internacionales. Sin embargo, si bien es una línea que en una rápida lectura se puede observar, no sería del todo correcto, ya que el CAPBA es un polo entre ese magma rizomático de creadores, programas de formación, festivales, productoras. Se trata de un fenómeno expansivo y multiplicador, no solo porque Campusano es uno de los creadores y fundadores del CAPBA, sino también porque los movimientos de los clústeres regionales e internacionales muchas 
veces ya habían sido gestados con anticipación al impulso del cineasta quilmeño. Así, el movimiento audiovisual de la Provincia de Buenos Aires pasaba a ser un agente más en la continuidad y un refuerzo en las modalidades de producción. Estos lazos positivos, lejos de ser unidireccionales, se componen como un resultado multidireccional. Por ofrecer un ejemplo, los vínculos con Inmersivefilms y Virtual ${ }^{\circ} 360$ nutrieron la estética del CAPBA en tanto que permitieron acceder a una nueva tecnología. Cambios estéticos, nuevas temáticas y la implementación de formatos renovadores trascienden el origen de Cinebruto. Asimismo, la multiplicidad de directores de las diversas naciones y regiones contempla variedad de estéticas, más allá de que exista la referencia al CAPBA y que este clúster haya apoyado las producciones.

Sólo para ahondar en la explicación, si imaginamos una línea de tiempo, primero existe Cinebruto que comienza a expandirse, a generar un movimiento centrífugo con su trabajo y a inspirar otras producciones desde su modo de producción y desde su estética. Allí es donde se aloja una primera estructura arbórea, un tronco común, que se bifurca hacia nuevas miradas. En un segundo momento cronológico nace el CAPBA, con su carácter expansivo, centrífugo y centrípeto, y a su vez rizomático por sus resultados estéticos, por la formación de talleres, programas y festivales en los que José Campusano y Cinebruto son un componente entre otros tantos. Un último núcleo temporal de la línea que estamos trazando corresponde a la Red de clústeres, a la que ya se le atribuye un carácter múltiple en toda su estructura. Ahora bien, hay que comprender que en cada instancia temporal ya existían otras productoras y otros clústeres, entre ellos el de Bariloche, que luego se asocian para finalmente crear la Red.

El mecanismo del rizoma también genera, dentro de la estética de los films que analizamos, un quiebre donde se suspende el tipo de forma y contenido. No obstante, vuelve a regenerarse y retoma los compromisos sociales, instala los rodajes cooperativos, las instancias comunales y las inquietudes, que independientemente de que pertenezcan a diversas localidades geográficas, componen regiones históricas dispuestas a dialogar entre sí. En este sentido, las temáticas tales como el exilio, la violencia de género, las luchas por la diversidad sexual, las crisis sociales, las marginaciones, etc. son un punto común que aúna gran parte del corpus, no solo el elegido en este artículo sino también, el producido por los clústeres.

Por último, quisiera agregar que los cuatro ejes elegidos para pensar: la producción de Cinebruto, la creación del CAPBA, la participación de Festivales y las características de las estéticas; articulan una dinámica dentro del movimiento sobre el concepto de lo regional. En este caso la expansión al exterior, incluso más allá de los límites de Latinoamérica, promueven ese diálogo de resistencia que retoma los conflictos mencionados en diversas latitudes. 


\section{Referencias bibliográficas}

Campo, J.; Lusnich, A. (2018). "El cine argentino y su dimensión regional”. Aura. Revista de Historia y Teoría del Arte. 8, pp. 2-7.

Campodónico, H. (2014). "Argentina”. En Dragón Gumucio, A. (Comp) El cine comunitario en América Latina y el Caribe, (pp. 75-101). Colombia, Bogotá: FSCL-Fes Communication.

Deleuze, G.; Guattari, F., (2004). "Introducción: Rizoma”. En G. Deleuze \& F. Guattari, Mil mesetas. Capitalismo y esquizofrenia, (pp. 9-32). España: Pretextos.

Heredia, E. (1997). La región en la globalización y en la historia de las relaciones internacionales y latinoamericanas. Revista Ciclos, VII, 1 er. semestre.

Heredia, P. (2012). "Propuesta para un estudio de las operaciones políticas de regionalización cultural en la literatura argentina”. En A. Nalim, L. Massara, y R. Guzmán (directoras.) Literatura del Noroeste Argentino. II, (pp. 19-34). Argentina, San Salvador de Jujuy: UNJU.

Lencina, V, (2017). "Seres disfuncionales. La representación de lo marginal en la trilogía de Raúl Perrone: Labios de churrasco (1994), Graciadio' (1997) y 5 pal' peso (1998)". Argus-a. Artes y Humanidades, 23, s/d.

Molfetta, A. (2017). "De la vanguardia a la resistencia. La teoría del Tercer Cine revisada por el cine comunitario". En A. Molfetta (organizadora) Cine comunitario argentino. Mapeos, experiencias y ensayos, (pp. 105-130). Argentina, Buenos Aires: Teseo.

Molina, H. y F. Varela (2018). Regionalismo literario: historia y crítica de un concepto problemático.Argentina, Mendoza: Universidad Nacional de Cuyo. Secretaría de Ciencia, Técnica y Posgrado.

Olivera, A. (2017). "La productora Cinebruto, las películas de José Campusano y la experiencia del Clúster Audiovisual de la Provincia de Buenos Aires". En A. Molfetta (organizadora) Cine comunitario argentino. Mapeos, experiencia y ensayos, (pp. 131-158). Argentina, Buenos Aires: Teseo.

Prividera, N. (2014). El país del cine para una historia politica del nuevo cine argentino, "José Campusano: Cine en bruto". (pp. 78-81). Argentina, Córdoba: Los ríos.

Serafini, C. (2018). "Festivales de cine independiente: una galaxia que no sólo gira alrededor de Buenos Aires". Aura. Revista de Historia y Teoría del Arte, 8, pp. 165-182.

Trombetta, J. (2019). “Cine con vecinos: el fenómeno Saladillo”. Imagofagia, 20, s/d

Trombetta, J. (2020). "Cines de la tierra: cineastas del conurbano y provincia de Buenos Aires." Revista Argus-a. Artes y Humanidades, 37, s/d.

Velazquez, V. et al (2016). Primer Anuario CAPBA. Buenos Aires: Veroka Velázquez. 